\title{
CUANDO CAIGA FRANCO. LAS PROPUESTAS EDUCATIVAS PARA ESPAÑA DESDE EL EXILIO (1945)\&
}

\author{
When Franco Falls. Educational Proposals for Spain from Exile \\ (1945)
}

\author{
José Ignacio Cruz Orozco ${ }^{\beta}$ y Sandra García de Fez \\ Fecha de recepción: 11/10/2018 • Fecha de aceptación: 17/10/2018
}

Resumen. Finalizada la Segunda Guerra Mundial en 1945, fueron muchos los que creyeron que el fin del conflicto supondría la caída del franquismo, el regreso del gobierno republicano y la vuelta de la democracia a España. Desde el exilio, el retorno estuvo muy presente en publicaciones, reuniones, manifiestos y acciones políticas, especialmente en México y en Francia. Entre los temas tratados en los círculos de los desterrados con mayor implicación política e intelectual sobresalió la educación, dada la importancia que se le daba a la formación de las nuevas generaciones de españoles que deberían de retomar los principios y valores republicanos. El artículo examina tres documentos con propuestas de la política educativa a seguir tras la restauración republicana, efectuadas desde los idearios republicano-socialista y libertario. También se analizan las iniciativas llevadas a cabo en esas fechas en suelo francés para mantener la identidad española entre los exiliados más jóvenes.

Palabras clave: Segunda República española; Exilio; Franquismo; Política educativa.

\footnotetext{
\& Los autores del artículo son miembros del grupo de investigación en Políticas, Interculturalidad y Sociedad (POLISOC), adscrito al Departamento de Educación Comparada e Historia de la Educación de la Universitat de València-Estudi General.

${ }^{\text {B }}$ Departamento de Educación Comparada e Historia de la Educación, Facultad de Filosofía y Ciencias de la Educación, Universitat de València, Avda. Blasco Ibáñez, 30, 46010, València, España. jose.i.cruz@uv.es

\$ Departamento de Educación Comparada e Historia de la Educación, Facultad de Filosofía y Ciencias de la Educación, Universitat de València, Avda. Blasco Ibáñez, 30, 46010, València, España.sandra.defez@uv.es
}

Cómo citar este artículo: Cruz Orozco, José Ignacio y Sandra García de Fez. «Cuando caiga Franco. Las propuestas educativas para España desde el exilio (1945)». Historia y Memoria de la Educación 9 (2019): 101-138. 
Abstract. After World War II in 1945, many people believed that the end of the conflict would lead to the fall of Francoism, the comeback of the Republican government and a return to democracy in Spain. This idea of the return had a significant presence in publications, meetings, manifestos and political actions, especially in Mexico and France. Education stood out among the topics addressed by the exiled groups that had a greater political and intellectual implication. The education of the new generations of Spaniards, who were supposed to resume the republican principles and values, was extremely important. This article examines three documents that include recommendations on the educational policy to be implemented after the Republican restoration. These proposals were drawn up from the republican, socialist and libertarian ethoses. This paper also reviews the initiatives carried out on French soil at that time to maintain, among the younger exiled, a Spanish identity.

Keywords: Spanish Second Republic; Exile; Francoism; Education policy.

\section{INTRODUCCIÓN}

El exilio republicano de 1939 está considerado como uno de los más destacados acontecimientos de la historia española del siglo xx. Epílogo final de la Guerra Civil, supuso el abandono definitivo de sus hogares de miles de personas, la mayoría de las cuales cruzaron la frontera francesa en la primera mitad de dicho año, cuando la represión franquista se extendió por todo el territorio español. Ese amplio colectivo, compartía aspectos comunes como la adscripción republicana y el consiguiente rechazo al gobierno autoritario del general Franco. Pero más allá de esa urdimbre unitaria, los aspectos que separaban e, incluso, enfrentaban a los distintos sectores políticos y sociales del destierro, eran numerosos y destacables. La inmensa mayoría estaban vinculados, con mayor o menor intensidad, a ideologías partidistas con diferentes programas de actuación y distinto compromiso o adhesión al proyecto republicano. Estos enfrentamientos no brotaron fuera de las fronteras españolas, sino que arrastraban fuertes discrepancias no resueltas en España.

Igualmente, debe tenerse en cuenta que, ya fuera de su tierra natal, los republicanos se vieron forzados a dispersarse enfrentándose a la necesidad de diseñar estrategias personales de supervivencia y adaptación a las sociedades de acogida. Teniendo en cuenta dichas circunstancias, 
el estudio de cualquiera de sus múltiples e interesantes facetas, supone abordar realidades dispares, ante las cuales debe primar una equilibrada mirada que tenga en cuenta las divergencias de calado que caracterizaron al destierro.

Desde una perspectiva más general, los especialistas identifican diversas etapas en la historia del exilio. La primera abarcaría casi toda la década de 1940 y su principal característica sería la firme convicción en la inminente caída del régimen franquista y, en consonancia, la percepción del desarraigo como un capítulo vital de corta duración. Esa creencia, casi certeza, regía la vida diaria de miles de familias y se consolidaba con los grupos de amistades y en los centros de reunión. Así, según la profesora Alted, ${ }^{1}$ la década de los cuarenta se caracterizó por la lucha contra el franquismo en pro de la restauración de la República.

Dentro de esa coyuntura, los expatriados defendieron y emprendieron importantes proposiciones. Nuestro trabajo se va a centrar en algunas de ellas, concretamente en las medidas de actuación a seguir en política educativa cuando se produjera el regreso a España, así como en algunas acciones, menos conocidas, que facilitaran ese empeño. En torno a la educación se diseñaron algunas de las propuestas reformistas más ambiciosas de los gobiernos republicanos, las cuales, en gran medida, fueron llevadas a la práctica entre 1931 y 1933 y en 1936 con el Frente Popular. En consecuencia, no debe extrañarnos que dentro del proceso de reorganización y dinamización que llevaron a cabo los distintos grupos en los momentos finales de la Guerra mundial, el interés por la educación ocupara cotas elevadas. Dentro de la permanente denuncia de la ilegalidad del gobierno franquista y la búsqueda de la condena internacional, las cuestiones sobre enseñanza resultaban prioritarias por su cercanía con el proyecto republicano y el papel preponderante en la restitución de la democracia.

\section{PENSANDO EN EL REGRESO}

En el artículo analizamos tres documentos de forma pormenorizada y expondremos, más brevemente, algunas de las acciones educativas que diversas entidades republicanas llevaron a cabo en terreno francés.

\footnotetext{
${ }^{1}$ Alicia Alted, La voz de los vencidos. El exilio republicano de 1939 (Madrid: Aguilar, 2005), 311.
} 
El primero de esos documentos es la ponencia sobre Educación redactada por la Comisión para el estudio de los problemas españoles, la cual fue publicada en la Ciudad de México. ${ }^{2}$ La Comisión había sido creada por la Unión de Profesores Universitarios Españoles en el Extranjero (UPUEE). El segundo es un folleto escrito por el maestro y pedagogo libertario José de Tapia, titulado Ensayos sobre la Organización de la Educación Nacional, y editado en Francia por Ediciones Tierra y Libertad. ${ }^{3}$ Por último, el tercer texto, mucho más reducido que los dos anteriores, es el Dictamen sobre enseñanza aprobado por el Comité Nacional del Movimiento Libertario Español-CNT en el congreso celebrado en París los días 1 y 2 de mayo de $1945 .{ }^{4}$

No hemos localizado otros documentos similares ni referencia alguna en publicaciones especializadas, lo cual no es óbice para pensar que, debido a la dispersión de la documentación sobre el exilio pedagógico español de 1939 en archivos públicos y privados ubicados en diversos países americanos y europeos, pueda aparecer algún otro texto similar a los que ahora presentamos.

Se trata de tres fuentes documentales de gran interés que, sin llegar a ser inéditas, ya que fueron publicadas, han carecido de atención por parte de estudiosos del exilio de 1939. Se da la feliz circunstancia de que en este mismo monográfico se reproducen íntegramente los tres textos en la Sección de Documentos, por lo cual la persona interesada podrá realizar su propia lectura. Cada texto cuenta con una introducción que antecede la reproducción del mismo, por lo que remitiremos a dicha sección para evitar duplicidades.

Editados en 1945, ven la luz en un contexto crucial para el exilio español. A principios de mayo de ese mismo año, Alemania firmó su capitulación, dando por finalizada la guerra mundial en Europa. Japón, la única potencia del Eje que se mantenía en armas, se rindió el 14 de

${ }^{2}$ Comisión de Estudio de los Problemas Españoles, Educación (México DF: Talles tipográficos de B. Costa Amic, 1945) 23 páginas.

${ }^{3}$ José de Tapia, Ensayos sobre Organización de la Educación Nacional (s.l.: Ediciones Tierra y Libertad, 1945), 47 páginas. Folleto n. ${ }^{\circ} 8$ de la Colección Pedagógica.

${ }^{4}$ «Dictamen correspondiente al apartado f) del punto 9 que trata del orden cultural y de educación nacional», en Movimiento Libertario Español. C.N.T. en Francia. Comité Nacional, Memoria del Congreso de Federaciones Locales celebrado en París del 1. ${ }^{\circ}$ al 2 de mayo de 1945. Dictámenes (s.l.: Comité Nacional, 1945), 21-25. 
agosto, tras la explosión de dos bombas nucleares sobre Hiroshima y Nagasaki. En esos momentos, los procesos de reorganización territorial y política de los territorios ocupados por los Aliados, se vieron impulsados. Entre abril y junio de ese mismo año, se celebró la Conferencia de San Francisco, en donde se aprobó la Carta de las Naciones Unidas, una de las vigas maestras sobre las que debía articularse la nueva política internacional.

Teniendo en cuenta esa coyuntura tan excepcional, los republicanos españoles realizaron importantes esfuerzos para ganar presencia y que las potencias vencedoras - Estados Unidos, Rusia, Inglaterra y Francia- tuvieran en cuenta sus demandas en las reuniones que venían celebrando. Con esa finalidad se reconstituyeron las Cortes Republicanas Españolas en el exilio, las cuales se reunieron en enero, agosto y noviembre de 1945 en la capital mexicana, con el objetivo de concitar intereses comunes entre los divididos grupos políticos, buscando compromisos para reconstituir una estructura política fuera de España. ${ }^{5}$

Finalmente, en noviembre de 1945, se consiguió formar el primer gobierno de la República Española en el exilio —el denominado de la esperanza- presidido por José Giral, destacado político republicano. Al principio, tuvo su sede en la Ciudad de México, trasladándose a París en la primavera del año siguiente, entendiendo el acercamiento geográfico como un punto a favor en la lucha por forzar el cambio de régimen en España y la vuelta a la República. ${ }^{6}$ En este sentido, los tres documentos que se analizan, vieron la luz en unas fechas en que se estaba negociando la reorganización política de los países europeos tras la guerra, momento clave para las demandas del exilio republicano español, las cuales finalmente quedaron fueras de las prioridades geopolíticas del momento.

\footnotetext{
${ }_{5}^{5}$ Alted, La voz de los vencidos, 321, y Francisco Giral, «Actividad de los gobiernos y de los partidos republicanos», en El exilio español de 1939, vol. II, dir. José Luis Abellán (Madrid: Taurus, 1976), 204-207. Para una exhaustiva revisión de las publicaciones sobre el exilio político español consultar: Jorge de Hoyos, «La historiografía sobre refugiados y exiliados políticos en el siglo xx: el caso del exilio republicano español de 1939», Ayer. Revista de Historia Contemporánea 106 (2017): 293305.

${ }^{6}$ Giral, «Actividad de los gobiernos», 207-210.
} 


\section{LA PONENCIA SOBRE EDUCACIÓN DE LA COMISIÓN PARA EL ESTUDIO DE LOS PROBLEMAS ESPAÑOLES (MÉXICO, 1945)}

Los documentos analizados son de gran interés. Dos de ellos son relativamente amplios, y recogen en sus páginas ambiciosos proyectos educativos, los cuales guardan relación directa con la política educativa reformista llevada a cabo durante los gobiernos de la Segunda República. Por motivos de espacio, debemos limitarnos a examinar algunos de los elementos que consideramos más relevantes, siguiendo el mismo orden en los que los estamos refiriendo. En primer lugar, la ponencia de la Comisión editada en México, después el texto redactado por José de Tapia en Francia y, finalmente, el Dictamen del congreso libertario celebrado en París. Hemos elegido ese orden, para facilitar el análisis ateniéndonos al país donde fue escritos y la adscripción política de los autores, de corte anarquista los dos editados en Francia. Por otro lado, el de la Comisión y el de Tapia, permiten realizar comparaciones con relativa facilidad, ya que su estructura y nivel de concreción también presentan bastantes puntos de contacto. En cambio, el tercero presenta rasgos sensiblemente diferentes, por el tipo de publicación que es y por una autoría colectiva fruto de un debate político interno.

Centrándonos ya en el documento editado en la Ciudad de México, debemos precisar algunos aspectos sobre su autoría. La Comisión que lo redactó surgió de la UPUEE, como ya se ha indicado, entidad creada en París a finales de 1939 para vincular a los académicos exiliados asentados en diversos lugares de Europa y América. ${ }^{7}$ El grupo más numeroso y activo acabó instalándose en México y fue el que lideró la redacción de este texto. ${ }^{8}$ La Unión desarrolló un buen número de interesantes

\footnotetext{
7 José M. Cobos Bueno et al., «Reunión de la Unión de Profesores Universitarios Españoles, UPUEE», Abaco: Revista de cultura y ciencias sociales 42 (2004): 61-74.

${ }^{8}$ José María López Sánchez, «El exilio científico republicano en México: la respuesta a la depuración», en La destrucción de la ciencia en España. Depuración universitaria en el franquismo, dir. Luis Enrique Otero Carvajal, (Madrid: Editorial Complutense, 2006), 177-239. Sobre la UPUEE, véase el artículo de Jaume Claret Miranda incluido en la sección monográfica de este número: Jaume Claret Miranda, «La Unión de Profesores Universitarios Españoles en el Exilio». Historia y Memoria de la Educación 9 (2019): 295-317. Para mayores referencias sobre el proceso que llevó a la constitución de la Comisión para el Estudio de los Problemas Españoles y de la ponencia que redactó el documento nos remitimos a la introducción que precede a su reproducción en la sección de documentos de este mismo monográfico: José Ignacio Cruz Orozco, «La propuesta sobre edu-
} 
iniciativas, como la que estamos analizando, pero conforme sus miembros fueron asentándose en los países de acogida, las actividades fueron menguando hasta prácticamente desaparecer a mediados de los años 50.

Quizá la actividad más destacada que llevó a cabo esa entidad, fue la reunión celebrada en octubre de 1943 en La Habana, en la cual se acordó crear una comisión para estudiar de los problemas españoles. Esta se organizó, a su vez, en varias ponencias, una de las cuales se dedicó a las cuestiones educativas. Se eligió como presidente al profesor Joaquín Xirau, y estuvo integrada por, Enrique Rioja, Rubén Landa, Luis Santullano, Antonio Ballesteros, Pedro Martín Navarro, José Peinado Altable y Domingo Tirado Benedí y Francisco Giral, farmacéutico y químico, profesor universitario en España y en México e hijo de José Giral, quien en 1945 presidió en primer gobierno de la República Española en el exilio. ${ }^{9}$

Se trataba de un conjunto muy selecto de destacados pedagogos y profesores, especialistas en las diversas etapas del sistema educativo y con una amplia y brillante trayectoria profesional. Santullano, Ballesteros, Peinado y Tirado, habían comenzado su carrera profesional trabajando como maestros. Posteriormente, con esfuerzo y tesón habían llegado a ser inspectores o a formar parte de los claustros de las escuelas normales. Concretamente, Luis Santullano estuvo muy vinculado a la Institución Libre de Enseñanza (ILE), desempeñando una intensa labor en la secretaría de la Junta de Ampliación de Estudios y en la del Patronato de las Misiones Pedagógicas. En el exilio mexicano siguió la misma senda, y trabajó en la secretaría de El Colegio de México. ${ }^{10}$ Antonio Ballesteros, por su parte, destacó en España como formador de maestros y llegó a ser inspector general de enseñanza durante la Guerra Civil. Estuvo vinculado a la Federación de Trabajadores de la Enseñanza (FETE),

\footnotetext{
cación de la comisión para el estudio de los problemas españoles (1945)». Historia y Memoria de la Educación 9 (2019): 631-672.

9 Andoni Garritz, «Francisco Giral González: un verdadero maestro», Revista de la Sociedad Química de México 46, no. 2 (2002): 74-76.

10 Etelvino González López, «El pedagogo Luis Álvarez Santullano», Cuadernos de la Cátedra Miguel de Unamuno 48 (2010): 119-175
} 
integrada en la socialista Unión General de Trabajadores (UGT), tanto en España como en el exilio. En México trabajó como profesor en diversas escuelas normales de ese país.

El rasgo más destacado de la trayectoria José Peinado Altable fue su interés por la psicología. Maestro y profesor de normales, publicó en 1934 los primeros manuales de psicología para estudiantes de magisterio que se editaron en nuestro país. Continuó con esa misma línea de trabajo e investigación durante su exilio en México y Venezuela. ${ }^{11} \mathrm{Fi}$ nalmente, Domingo Tirado Benedí, antes de la guerra también había regentado diversas escuelas y ejercido posteriormente como inspector. A partir de 1939, fue profesor en el Instituto Luis Vives de México, uno de los colegios del exilio y profesor de escuela normal, desarrollando, de forma paralela, una destacada tarea editorial en ese país. ${ }^{12}$

Otros tres de los integrantes, Landa, Xirau y Rioja, acumulaban una amplia experiencia en bachillerato y culminaron su carrera docente en la universidad. Enrique Rioja Lo Bianco era biólogo y había trabajado como profesor de ciencias naturales en institutos, - dirigiendo varios de ellos, entre otros, el Instituto Obrero de Valencia- la Escuela de Superior del Magisterio y en Universidad Central de Madrid. En México se vinculó desde su llegada en 1939 al Instituto de Biología de la Universidad Autónoma de México (UNAM), donde desplegó una prolífica trayectoria docente e investigadora. ${ }^{13}$ Rubén Landa era maestro, licenciado en filosofía y doctor en derecho, ejerció como profesor de instituto y estuvo especialmente vinculado a la ILE. Militante azañista destacado, en México fue nombrado en 1942 director de Instituto Luis Vives. En los años posteriores fue docente en instituciones de ese país y de los Estados Unidos. ${ }^{14}$ Por último, Joaquín Xirau, también presenta una trayectoria profesional coincidente en parte con los dos anteriores. Profesor

\footnotetext{
${ }^{11}$ Tomás Peláez Reoyo, Peinado Altable (1909-95). Aportaciones a La Psicología y Educación (Valladolid: Universidad de Valladolid, 1998).

12 Víctor Manuel Juan Borroy, «El pedagogo aragonés Domingo Tirado Benedí. Notas sobre su vida y obra», Anales. Anuario del Centro de la Universidad Nacional de Educación a Distancia en Calatayud 9 (2001): 117-128.

13 Juan Luis Cifuentes Lemus, «Enrique Rioja Lo Bianco (1895-1963»), Revista de la Universidad 536-537 (1995): 64-65.

${ }_{14}$ Modesto Miguel Rangel Mayoral, Rubén Landa Vaz, un pedagogo extremeño de la Institución Libre de Enseñanza en México (Badajoz: Editora Regional de Extremadura, 2006).
} 
de filosofía en instituto y en la universidad, fue decano de la Facultad de Filosofía y Letras de la Universidad de Barcelona entre 1933 y 1939. En el exilio mexicano trabajó en la Casa de España y en la Facultad de Filosofía de la UNAM. Tuvo una identidad política destacada como militante y dirigente de la Unión Socialista de Cataluña. ${ }^{15}$

Como nos informan estos breves trazos biográficos, todos ellos contaban con un amplio conocimiento de la realidad de las distintas etapas del sistema educativo español, desde la escuela primaria hasta la universidad. También aportaban miradas específicas, desde la gestión administrativa, la psicología, la formación de docentes y las didácticas específicas de diversas materias. A su modo, representaban las corrientes pedagógicas renovadoras más destacadas, con una presencia sobresaliente del institucionismo, y los idearios políticos republicano y socialista. Todo lo cual quedó plasmado en el documento en cuestión, como se podrá comprobar.

Volviendo al texto de la ponencia, consta de 23 páginas divididas en una introducción, un apartado de normas generales, otro dedicado a la enseñanza primaria, un tercero sobre la enseñanza media, el siguiente centrado en la cultura superior y el último titulado: «Intercambio universitario y relaciones culturales, especialmente con América». Cada una de las secciones, incluye una serie de propuestas relativamente concretas. El apartado de normas generales y primera enseñanza enumeran 19 medidas; el de enseñanza media 29; el de educación superior 31 dedicadas a universidades y escuelas superiores, a los que había que añadir cinco a la investigación científica y cuatro al tesoro histórico-artístico y servicios de Archivo, Bibliotecas y Museos. En el último apartado, dedicado al intercambio universitario, se especifican seis medidas, aunque la última de ellas se concreta, a su vez, en 13 objetivos más específicos.

El primer lugar debe señalarse que, como no podía ser de otro modo, el texto muestra una voluntad inequívoca de retomar la acción de la política educativa española donde las circunstancias habían obligado a dejarla. La primera de las normas generales, a modo de pauta

\footnotetext{
15 José Luis Martín Ramos, «La Unió Socialista de Catalunya (1923-1936)», Recerques: Història, economia i cultura 4 (1974): 155-190.
} 
básica en el cual se sustenta todo el documento, enuncia lo siguiente: «Se reanudará y proseguirá la obra realizada por la República en el dominio de la instrucción y educación públicas». ${ }^{16}$ En consecuencia, en las páginas de la Ponencia abundan las referencias a esa voluntad de continuidad, especialmente relevantes en relación con que en el escrito se denomina «núcleos de selección». A saber: escuelas modelos, Institutos-Escuela y las experiencias de autonomía universitaria llevadas a cabo en Madrid y Barcelona. Para todos ellos se marcaba que «lo único que cabe hacer es seguir fomentándolos y multiplicarlos con tacto y cautela siempre que las condiciones lo permitan». Ese mismo propósito se manifiesta para la Junta de Ampliación de Estudios y los centros que dependían de ella. ${ }^{17}$

Esa pauta de continuidad no impedía una seria llamada a la moderación, ante la incertidumbre de la situación que se encontrarían a su regreso. Dependiendo de las circunstancias, no se proponía «una acción quirúrgica», sino más bien «una ordenación terapéutica y de vigorosa higiene». Es más, en el caso de que aquella «fuese imprescindible», los redactores apelaban a la responsabilidad de los dirigentes que tuvieran que llevarla a cabo, deseando «que Dios ponga tiento en las manos que la ejecuten». ${ }^{18}$ Resulta interesante la llamada a la templanza, y llamativo ese marcar distancias hacia las manos que deberían ejecutar el programa, proclamada por una comisión repleta de cuadros muy destacados de la administración educativa republicana.

Otro elemento bien patente a lo largo del documento, es la orientación claramente estatista, en plena concordancia con lo que había sido la política educativa a partir de 1931, pero que ahora se retoma con mayor insistencia. Ya en la introducción se afirmaba que «el Estado tiene el deber de proveer a todas las necesidades del país, en lo relativo a la enseñanza primera y media, procurando que sus escuelas sean, en todos los aspectos las mejores». Así, por ejemplo, se indica expresamente que sus locales, aunque sencillos e higiénicos serían inmejorables y se proponía un plan específico para atender y cuidar las escuelas rurales dotándolas de material moderno. En esa misma línea, se insistía sobre

\footnotetext{
${ }^{16}$ Comisión, Educación, pp. 7-39.

17 Comisión, Educación, 7-8 y 25.

18 Comisión, Educación, 7.
} 
las funciones de la inspección educativa, otorgándole un rol destacado de supervisión, a la par que de fomento de la innovación, por lo que sería "preciso crear gran número de plazas». ${ }^{19}$

Debe añadirse, que los miembros de la ponencia habían tomado buena nota de los problemas de coordinación surgidos entre el gobierno central y los de las autonomías, en especial durante la Guerra Civil, y, para prevenirlos, recomendaba la creación de "Consejos mixtos de enseñanza». ${ }^{20}$ Con idéntico propósito integrador, se citaba la necesidad de coordinar todos los grados de enseñanza y especialmente de la enseñanza media —los institutos, las escuelas de trabajo, industriales, artes y oficios, bellas artes, etc.- y las facultades y escuelas superiores universitarias. ${ }^{21}$

Como contrapeso inevitable a todas esas declaraciones a favor de lo público, la ponencia no se olvidó de la libertad de enseñanza. Ya en la introducción se mostraba contraria al monopolio estatal de la enseñanza y juzgaba beneficiosa la existencia de escuelas libres, «que sirvan a las del Estado de aliciente y de acicate». Con ellas se establecería una relación de colaboración, aunque advirtiendo a la Administración para que no olvidara las tareas para supervisar el cumplimiento de la normativa. Pero esa declaración en pro de la libertad de creación de centros docentes, se le colocaba un límite bien preciso. Solo se estimaba conveniente para la primera y segunda enseñanzas. Por el contrario, no debían existir centros de enseñanza superior organizadas por «entidades particulares». Esa limitación se intentaba compensar señalando que en la universidad se regiría con «la más absoluta libertad para profesores y alumnos». ${ }^{22}$

Íntimamente relacionado con lo anterior, el texto mantenía el principio laicista que había caracterizado la educación republicana, situando la enseñanza religiosa bajo la esfera de las respectivas confesiones e incluyendo en el sistema educativo, exclusivamente, el estudio «de la religión desde el punto de vista histórico». Sobre este punto concreto versó

\footnotetext{
19 Comisión, Educación, 15.

${ }^{20}$ Comisión, Educación, 12.

${ }^{21}$ Comisión, Educación, 8, 18 y 21-23.

${ }^{22}$ Comisión, Educación, 9 y 12.
} 
el voto particular formulado por Xirau, al cual se adhirió Giral y que se incluyó en la última página del documento. Ambos mantuvieron una redacción anterior, muy parecida a la finalmente aprobada, pero en la cual se hacía hincapié en un par de matices. Uno, señalando que el conocimiento histórico y filosófico se centraría especialmente en la religión cristiana y el segundo, especificando que la enseñanza religiosa se haría, en todo caso, fuera de los centros de enseñanza. ${ }^{23}$

Otro principio destacado, repetidamente señalado, es la voluntad por democratizar la enseñanza. En relación con ello se indica expresamente que la enseñanza debía ser obligatoria y gratuita hasta los 14 años, la aspiración «a que la segunda enseñanza sea posible para todos» y el mantenimiento provisionalmente del bachillerato para obreros, con la finalidad de «corregir, en alguna medida, las deficiencias del sistema de privilegio que hemos heredado». También se proclamaba que todo estudiante que demostrase la suficiente capacidad debía cursar el bachillerato y acceder a la universidad. Para facilitarlo se proponía establecer un amplio sistema de becas. ${ }^{24}$ En este aspecto la ponencia había sido sensible a algunas de las demandas más insistentes de las organizaciones obreras, y mantenía el emblemático bachillerato obrero, puesto en marcha en plena Guerra Civil cuando el comunista Jesús Hernández ocupó la cartera de instrucción pública.

Igualmente, relacionados con los planteamientos democratizadores, la ponencia efectuó indicaciones sobre la educación de las mujeres. Señaló que todas las normas del texto deberían aplicarse por igual a hombres y mujeres sin distinción, y, en buena lógica, que el principio de coeducación debía aplicarse a toda la organización educativa que se proponía. Para disipar recelos, se recordaba que en España se había aplicado la coeducación de un modo ejemplar y que «bien dirigida es, sobre todo aconsejable desde el punto de vista de una sana moral». ${ }^{25}$

La idea más potente que se desprende de la lectura del texto, es la reafirmación en la bondad del modelo educativo de la República y la innegable voluntad de restituirlo y ampliarlo. Este principio fundamen-

\footnotetext{
${ }^{23}$ Comisión, Educación, 8 y 30.

${ }^{24}$ Comisión, Educación, 8, 13 y 15.

${ }_{25}$ Comisión, Educación, 11.
} 
tal aparece concretado, además de lo ya indicado, en multitud de aspectos, aunque aquí solo podemos incidir en algunos. Así, por ejemplo, se afirma en el punto dos de las normas generales, que «la enseñanza en todos sus grados habrá de tener una orientación liberal alejada de cualquier imposición dogmática». Lo que se complementaba en la página siguiente insistiendo en que tendría un enfoque integral, orientado en «un sentido activo, personal y tutelar y de íntima convivencia entre el maestro y el alumno». ${ }^{26}$

Resulta de interés destacar las llamadas especiales a potenciar una organización escolar «que comprenda todas las esferas de la educación humana», mencionando expresamente la formación intelectual, corporal, afectiva y del carácter. Igualmente, se insistía en «acabar con los restos pseudouniversitarios de la antigua enseñanza secundaria», reduciendo en lo posible el empleo exclusivo del libro de texto e impulsando la orientación escolar. Otro apunte destacado, es la introducción del estudio del gallego y el catalán en el bachillerato y la universidad, siguiendo los intentos durante los gobiernos republicanos de ir incorporando las lenguas propias a la enseñanza, en un incipiente reconocimiento de la plurinacionalidad de España. ${ }^{27}$

La ponencia se ocupó de la inclusión en el sistema educativo de grupos específicos como párvulos y personas con deficiencias cognitivas, sensoriales o con problemas crónicos de salud, los cuales en aquellas fechas veían muy limitado el reconocimiento de su condición como ciudadanos de pleno derecho y su incorporación a las aulas. ${ }^{28}$ Esa extensión de la acción pedagógica, también abarcaba otros espacios educativos que desbordaban el ámbito de la educación formal. Así, se advertía la necesidad de impulsar las colonias escolares, permanentes y de vacaciones, en todos los grados de enseñanza, «especialmente destinadas a los niños pobres». También se consideraba imprescindible «proseguir con la obra de las Misiones pedagógicas [...] poniéndolas bajo la advocación de su creador Manuel B. Cossío», único nombre propio que se menciona en todo el texto. ${ }^{29}$ Resulta imposible no percibir en es-

\footnotetext{
${ }^{26}$ Comisión, Educación, 12 y 13.

27 Comisión, Educación, 13 y 18.

${ }^{28}$ Comisión, Educación, 11 y 16.

${ }^{29}$ Comisión, Educación, 13.
} 
tos planteamientos, la innegable huella del pensamiento pedagógico de la Institución Libre de Enseñanza y del ideario más avanzado y progresista del magisterio y el profesorado republicano.

Otro eje que surca todo el documento, y del que pueden localizarse abundantes detalles, hace referencia a papel de la pedagogía dentro de la política educativa y del sistema de enseñanza que se estaba diseñando. La propuesta guardaba directa relación con la gran preocupación de los redactores en cuanto a la formación y selección del profesado, de los directores e inspectores, calificados como elementos personales de "cardinal importancia». Al respecto, la reforma de las escuelas normales debía seguir el modelo de la Escuela Normal de la Generalitat de Barcelona y, en el proceso, debían de jugar un papel destacado «las Secciones y Seminarios de Pedagogía de la Universidades de Madrid y Barcelona». Allí deberían formarse inspectores, directores de graduadas y profesores de normales, escuelas especiales y de esas mismas secciones universitarias. Además, las Secciones contarían con centros adscritos de primera y segunda enseñanzas, a modo de «centros de ensayo y reforma». ${ }^{30}$

Igualmente, se trazaba el itinerario formativo de los licenciados que quisieran ser profesores de segunda enseñanza, los cuales deberían de pasar por esas Secciones para alcanzar «una formación pedagógica y práctica que los capacite para su cometido». Pero la propuesta era más ambiciosa. Tras acabar esos estudios, los aspirantes ejercerían con nombramiento provisional y sólo alcanzaría el definitivo puesto en el escalafón si contaban con informes favorables de la dirección del centro, la inspección y superaban unas «pruebas teórico-prácticas complementarias». Por su parte, el profesorado en ejercicio debería reciclarse siguiendo cursillos en las Secciones de Pedagogía. ${ }^{31}$ Resulta reveladora la consideración del profesorado como elemento clave en la puesta en marcha de su propuesta educativa, recogiendo el testigo de las iniciativas formativas desarrolladas durante los años de la República y haciendo hincapié en la necesidad de una formación continua durante el ejercicio profesional.

\footnotetext{
30 Comisión, Educación, 14 y 17.

31 Comisión, Educación, 17 y 18.
} 
En las propuestas relativas a la Universidad, se aprecia que, además del reconocimiento de la complejidad de los estudios superiores, la ponencia había surgido en una asociación de profesores universitarios, con visiones e intereses bien concretos. De entre todas las propuestas, deben ser subrayadas las destinadas a mejorar la coordinación en el ámbito universitario, especificándose los niveles en los que debían de llevarse a cabo: entre las facultades de cada universidad; cada una de las facultades con las escuelas profesionales más vinculadas a su ámbito académico y las escuelas superiores con la universidad en su globalidad. Igualmente, se abogaba por continuar ampliando la autonomía universitaria y por la necesidad de incrementar las dotaciones para bibliotecas y laboratorios. También se incluía una sentida llamada para que la Universidad de Salamanca recuperara su pasado prestigio. ${ }^{32}$

Igualmente, se otorgaba una atención preferente al profesorado universitario. Se proponía detallar sus deberes, condiciones de permanencia y la necesidad de consolidar las funciones del profesorado auxiliar, más allá de la mera sustitución, y abría dicha figura a los funcionarios docentes de otros cuerpos. De forma coincidente, la formación pedagógica de los docentes universitarios, se encuentra bien detallada, ocupando un importante espacio en el texto.

Asimismo, se señalaba, y aquí resulta ineludible pensar en la sublevación de julio de 1936 y sus desastrosas consecuencias, que los aspirantes a oficiales del ejército tuvieran una mayor y mejor formación civil. Deberían contar al menos seis cursos de bachillerato antes de ingresar en una academia militar y, una vez allí, tendrían que acudir a la Universidad para seguir asignaturas como: matemáticas, historia, introducción a la filosofía y ética. ${ }^{33}$

También se enumeran medidas para el ámbito de la educación superior, que rompían el espíritu democratizador señalado anteriormente para la primaria y las enseñanzas medias. En el caso de las aulas universitarias, ese principio no tenía por qué aplicarse, más bien al contrario. La ponencia apostaba por marcar claras barreras selectivas, con la implantación de una prueba de ingreso para el alumnado de carácter

32 Comisión, Educación, 22 y 23.
${ }_{33}$ Comisión, Educación, 22 y 24. 
temporal, justificándola en que evitaría «una aglomeración de estudiantes excesiva y perjudicial». ${ }^{34}$ En esa misma línea claramente meritocrática, se consideraba «excesivo el número de Universidades existentes». Previendo posibles conflictos, la ponencia se decantaba, no exenta de cierto eufemismo, por «buscar la agrupación y concentración compensada de Facultades, Escuelas e Institutos». ${ }^{35}$

La última cuestión a resaltar, se relaciona con medidas más directamente vinculadas a la propia situación de los desterrados. Por un lado, se preveían mecanismos para convalidar estudios y títulos obtenidos por los más jóvenes durante su estancia en los países de acogida. ${ }^{36} \mathrm{Y}$ de otro, se exponían profusamente una serie de consideraciones sobre las relaciones que el nuevo régimen republicano debería establecer con los países americanos, nuevo hogar de miles de refugiados. Por ello, había un claro interés por la formación de los connacionales allí donde existieran colonias de emigrantes, y en señalado propósito de incrementar los intercambios universitarios de todo tipo, aumentando las ayudas, creando instituciones culturales, residencias de estudiantes y organizando cursos, conferencias y congresos. ${ }^{37}$

Este redescubrimiento de las repúblicas americanas, antiguos territorios del imperio español, les llevó a expresar un sentido deseo porque se procediera a una revisión de los programas de las asignaturas de historia, de mutuo acuerdo con los países hispanoamericanos. En ella debía primar «la crítica severa» de guerras, conquistas y luchas civiles, buscando "con gesto de generosa comprensión» un nuevo relato académico de esos episodios de la historia española, superando el enfoque nacionalista y avanzando hacia «una comprensión unitaria de los acontecimientos». ${ }^{38}$

El texto se asemejaba mucho a un programa de intervención política. Como tal, establecía un marco global de actuación con sus correspondientes pautas generales. Posteriormente, se proponían unos claros

\footnotetext{
${ }^{34}$ Comisión, Educación, 25.

${ }^{35}$ Comisión, Educación, 24.

${ }^{36}$ Comisión, Educación, 13.

37 Comisión, Educación, 28 y 29.

38 Comisión, Educación, 29.
} 
objetivos en cada etapa formativa y una cierta graduación en su consecución. Y, finalmente, se diseñaba un buen número de iniciativas reformadoras para llevar a cabo de manera prácticamente inmediata en todos los niveles del sistema educativo.

Las iniciativas suponían una plena reivindicación de la política educativa de los gobiernos republicano-socialistas y del Frente Popular, pese a contener el documento algunas medidas que suponían una cierta rectificación de dicha trayectoria. Nos referimos a las afirmaciones relacionadas con la libertad de enseñanza, más concretamente con la creación de centros, y a las repetidas propuestas para profundizar en la democratización de la enseñanza. Esas correcciones, apuntan a un debate interno con ciertas dosis de autocrítica.

\section{LA PROPUESTA DE JOSÉ DE TAPIA (FRANCIA, 1945)}

Desde los grupos libertarios también se elaboraron propuestas con un marcado tinte político, bajo el deseo de que fueran puestas en marcha tras el regreso a España. Hasta donde tenemos conocimiento, se formularon dos. La primera apareció en 1945 editada por la editorial Tierra y Libre en Francia. Se trataba de un trabajo de José de Tapia titulado Ensayos sobre la Organización de la Educación Nacional. El texto tiene una extensión de 47 páginas, de las cuales 12 corresponden al prólogo. Fue escrito, según el propio autor, a finales de 1943 y principios de 1944, mientras residía en la localidad francesa de Entrains-sur-Nohain, precisamente, en los momentos en que el ejército alemán comenzó a pasar a la defensiva y pudo vislumbrarse en el horizonte la liberación de Francia. Se trata de la reflexión personal de un notable educador y pedagogo con amplia experiencia profesional y sindical, pero que en esos momentos no ostentaba ninguna responsabilidad política. ${ }^{39}$ No puede considerarse un programa político de actuación en sentido estricto, aunque Tapia pretendió que fuera un documento de debate, y para ello detalla un buen número de fórmulas concretas de intervención. Debe considerarse, bajo nuestra perspectiva, como una valiosa contribución experta al incipiente proceso que se pensaba estaba a

\footnotetext{
${ }^{39}$ Fernando Jiménez Mier y Terán, Un maestro singular. Vida, pensamiento y obra de José de Tapia B. (México: Ediciones Robin, 1989).
} 
punto de iniciarse, ante la creciente expectativa por la inminente caída del régimen franquista y el final del exilio forzado de centenares de miles de compatriotas.

El texto se encuentra enmarcado en el ideario libertario, pero con un marcado sesgo personal, ya que incorpora destacadas adaptaciones particulares. Tapia deja traslucir en la redacción del documento, su amplia trayectoria en España como maestro nacional y las destacadas innovaciones pedagógicas de las que había sido promotor y protagonista. ${ }^{40}$ Una de las de mayor trascendencia fue la introducción de las técnicas educativas del pedagogo francés Celestin Freinet. ${ }^{41}$ No nos encontramos, por tanto, ante un texto doctrinal, ni ante un ejercicio de propaganda anarcosindicalista, pese a la editorial que lo publicó (Tierra y Libertad), sino que se trata, más bien, de una propuesta de reorganización escolar a tener en cuenta en la restauración de la democracia en España. Sus destinatarios no se encontraban reducidos a un sector ideológico, sino que presentaba una voluntad más integradora, buscando superar barreras partidistas. Se pensó «como posible y necesario» y para ser expuesto a la «opinión pública», con una llamada específica para que fuera debatido por las dos grandes centrales sindicales españolas, la socialista UGT y la anarcosindicalista Confederación Nacional del Trabajo (CNT) ${ }^{42}$

El maestro Tapia se mantuvo, sin embargo, fiel a algunos los principios de la pedagogía libertaria, efectuando repetidas alusiones a la libertad como eje fundamental de las propuestas. En el prólogo, redactado por Ildefonso González Gil, ya se enmarca convenientemente la cuestión, al señalar que una de las características principales del momento histórico que se estaba viviendo, era el conflicto entre «autoridad y libertad». ${ }^{43}$ Pero el dilema no solo resultaba clave desde la mirada de la coyuntura geopolítica. También era considerado esencial para la polí-

\footnotetext{
${ }^{40}$ Félix Carrasquer, Lo que aprendí de los otros (Zaragoza: Prensas de la Universidad de Zaragoza: Instituto de Estudios Altoaragoneses; Instituto de Estudios Turolense y Gobierno de Aragón, 2017), 127-132.

${ }^{41} \mathrm{Al}$ respecto resultan de gran utilidad los comentarios del profesor Antonio Viñao que acompañan la reproducción del texto en la sección documental de este número de la revista.

42 Tapia, Ensayo, 45 y 47.

${ }^{43}$ Idelfonso (González Gil), «Prólogo», en Tapia, Ensayo, 6.
} 
tica educativa en sí misma, lo que se ejemplificaba con una sentencia categórica: "No habrá niños libres con maestros esclavos». ${ }^{44}$

Del mismo modo, resulta significativo que dicha argumentación, prototípica del pensamiento educativo libertario, se encuentra bastante atemperada cuando el maestro Tapia desciende a concretarla. Aquí se constata el peso de su amplio recorrido profesional y el conocimiento directo de la práctica escolar. Durante décadas había ejercido en escuelas rurales, comprobando la necesidad de la iniciativa estatal para hacer viable el acceso a la educación en todos los rincones del país. A su vez, también había experimentado que la administración educativa tenía sus resquicios y permitía salirse de los caminos trazados, pudiéndose llevar a cabo en las aulas de las escuelas nacionales experiencias de innovación pedagógica tan destacadas como las freinetistas, de las cuales era conocedor directo y firme defensor.

Un elemento reseñable en que se pone de manifiesto ese posibilismo, lo encontramos en las funciones que atribuye al Estado. El maestro Tapia le reconoce un destacado rol como representante de la sociedad, que lo legitimaba para actuar como agente educativo, dictando «normas generales» y llevando a cabo medidas de control y supervisión. En concreto, sitúa bajo su responsabilidad elementos curriculares tan destacados como el establecimiento de los títulos oficiales y los contenidos mínimos para obtenerlos. ${ }^{45}$

Pero donde Tapia pormenoriza más esos aspectos, es cuando le atribuye la supervisión de las instituciones educativas, al considerar que la educación de la juventud precisa «un control constante». Para ello propone una reforma integral de la inspección de primera enseñanza, que debería ser ostentada por personal procedente del escalafón del magisterio cuidadosamente seleccionado, empleando el mismo modelo para la enseñanza secundaria. Al respecto, llega a afirmar en una de las páginas finales de su trabajo, que debe corresponder al Estado el control del sistema educativo en su totalidad, «desde la escuela a la Universidad». ${ }^{46}$

\footnotetext{
${ }^{44}$ Idelfonso, «Prólogo», 6.

45 Tapia, Ensayo, 14.

46 Tapia, Ensayo, 40-42 y 45.
} 
Ese enfoque claramente estatista, queda equilibrado, en parte, con la formulación de algunas cautelas para prevenir el riesgo del monopolio gubernamental. En consonancia con esta postura, efectúa repetidas llamadas a que se debe permitir y alentar la existencia de escuelas promovidas por otras entidades, en especial por los sindicatos. Incluso, desde una perspectiva más global, apunta que sería muy conveniente la existencia de «Instituciones de carácter libre y organizadas por el esfuerzo privado de los interesados, para lo que el Estado debería conceder ayuda fuerte y la aportación de Magisterio y Profesorado». ${ }^{47}$ Asimismo, José de Tapia mantuvo firmes sus creencias en otros extremos. Así, defendió con ahínco que los centros educativos y el profesorado tuvieran «libertad absoluta para el establecimiento de los métodos y procedimientos» pedagógicos, concibiendo así un interesante contrapeso a las competencias gubernamentales. ${ }^{48}$

Otro aspecto que destaca en el texto, es su marcado enfoque innovador. Al respecto, abogaba por redefinir la estructura del sistema educativo, con la finalidad de que estuviera totalmente integrada y permitiera superar las profundas diferencias pedagógicas, sociales, culturales y económicas existentes entre los distintos niveles de estudios: primaria, bachillerato y universidad. Tapia emplea la evocadora denominación de Escuela Unificada, e insiste en "que la Educación Nacional sea un todo armónico abarcando desde la Escuela maternal hasta la Universidad». Propone impulsar las escuelas maternales y guarderías infantiles para atender convenientemente a la infancia antes de la escuela primaria. ${ }^{49}$ Para la primaria y secundaria, defiende la creación de granjas-escuelas, ciudades infantiles y escuelas profesionales, estas últimas como itinerario paralelo y alternativo al bachillerato. En relación con este último, eleva la edad de inicio de dichos estudios de los 10 a los 12 años, finalizándolos a los 18, en un claro intento de incrementar el tiempo de formación de los jóvenes españoles. ${ }^{50}$

La publicación incorpora multitud de elementos y propuestas innovadoras, que respondían a sentidos problemas educativos y sociales del

\footnotetext{
47 Tapia, Ensayo, 17-18 y 45.

48 Tapia, Ensayo, 14.

49 Tapia, Ensayo, 17-19.

50 Tapia, Ensayo, 24, 32 y 34-35.
} 
sistema educativo. Siendo todos ellos de enorme interés, nos limitaremos a enumerar aquellos que ofrecen una visión más global de su enfoque político y educativo. Para Tapia, los institutos deberían funcionar en régimen de internado o semi-internado y con un diseño curricular mucho más amplio y ambicioso. El plan de estudios debería incorporar la práctica de «todos los deportes posibles» y un extenso programa de actividades culturales, exposiciones, salidas, visitas y excursiones, tanto en España como en el extranjero. ${ }^{51}$ Igualmente, para romper con el tradicional modelo dual y clasista que regía el sistema educativo español de la época, abogaba por la «selección racional, científica y natural de los alumnos» y defendía que, en todo momento y circunstancia, la política educativa debía estar presidida por los principios de gratuidad, obligatoriedad, coeducación, laicidad y apoliticidad. ${ }^{2}$

El manuscrito también insiste en la figura del profesor, que Tapia, como todos los impulsores de la renovación pedagógica, consideraba pieza clave a la hora de llevar a cabo con éxito cualquier medida reformadora. El autor, redefinió el rol del maestro, sumándole exigencias y responsabilidades con una orientación claramente paidocéntrica.

Nos vemos obligados a insistir reafirmando que el niño y el joven entre los seis y los diez y ocho años de edad necesitan la labor constante y sentida, profunda y abnegada, del Maestro, del conductor y no la del profesor que sin despreciarla ni subestimarla, comprendemos no es suficiente ni acertada. La misión social es eminentemente educativa, y solo cuando el ciclo evolutivo de nuestra juventud pueda considerarse cerrado, o superado, podemos prescindir del Maestro. ${ }^{53}$

Partiendo de esa premisa, dedica varios apartados al magisterio y al profesado de secundaria. Dentro del diseño de formación de ambos cuerpos docentes, concedió suma importancia a los Seminarios de Pedagogía, destinados a sustituir a las Escuelas Normales en todo lo referente a la formación del magisterio. ${ }^{54}$ Pero no se trataba de un sim-

\footnotetext{
51 Tapia, Ensayo, 32-33.

52 Tapia, Ensayo, 16-17.

53 Tapia, Ensayo, 32.

54 Tapia, Ensayo, 36-37.
} 
ple cambio de denominación. Los Seminarios deberían centrarse, como núcleo principal de trabajo, estudio y profundización, «en el grupo de las llamadas Ciencias Pedagógicas en general y muy especialmente en la Pedagogía, en la Psicología experimental y en los trabajos psicotécnicos». Por el contrario, la ampliación de conocimientos de las materias generales - como historia, geografía, ciencias, filosofía, etc.- debía de pasar a segundo término. ${ }^{55}$

Sin embargo, el propósito de esas nuevas instituciones docentes iba más allá. Como los maestros tendrían que actuar como modelos integrales de referencia para su alumnado, Tapia insistía en que se pondría «un exquisito cuidado en la fundamental educación de carácter» de los futuros enseñantes. Por ello, defendía que debían de funcionar en régimen de internado, para facilitar un sistema de trabajo más global e intensivo. ${ }^{56}$

Como se puede comprobar, los Seminarios de Pedagogía resultaban cruciales para la formación del magisterio y del profesorado de la enseñanza media. Este debía ser seleccionado entre «el Magisterio en activo mediante concursos especiales y con un mínimo de ejercicio». Posteriormente, los elegidos tendrían pasaban una etapa de formación universitaria de dos cursos en las Facultades de Ciencias o Filosofía y Letras, según su especialización. Una vez superados, empezaban a trabajar en su destino. Con ese novedoso itinerario formativo, Tapia buscaba renovar por completo los claustros de la enseñanza secundaria y oxigenar «el ambiente educativo» de los institutos. ${ }^{57}$

Otro aspecto especialmente relevante del texto que estamos analizando, y que ya ha aflorado anteriormente, se relaciona con el profundo interés de José de Tapia por las cuestiones de índole social. Al respecto, se mostró tajante, y debemos retomar como punto de partida un razonamiento ya citado: "la misión social es eminentemente educativa». ${ }^{58}$ Teniendo en cuenta lo estudiado hasta el momento y lo que sabemos de su pensamiento y trayectoria, no creemos malinterpretarlo si, para cla-

\footnotetext{
55 Tapia, Ensayo, 36.

56 Tapia, Ensayo, 36.

57 Tapia, Ensayo, 37.

58 Tapia, Ensayo, 32.
} 
rificar su posición, cambiamos el orden de los factores y señalamos que, para el maestro Tapia, la misión educativa presentaba, por encima de cualquier otra circunstancia, un inexcusable componente de compromiso social.

Ese claro posicionamiento se pone de manifiesto en bastantes ocasiones, como cuando razona la importancia de las guarderías infantiles para atender las necesidades de las mujeres obreras. «Necesidad que no se nos oculta proceden de la incomprensión y del egoísmo del régimen capitalista y del empleo del maquinismo [...] en beneficio exclusivo del Capital, como nueva divinidad absorvente (sic) y devoradora». Para él, cualquier acción educativa debía estar organizada para avanzar en «la formación espiritual de los niños en un ambiente natural y sano de solidaridad, colaboración y cooperativismo, base de la sociedad futura y libertaria». ${ }^{59}$

Pero, como ya hemos indicado en repetidas ocasiones, Tapia se preocupó por concretar los principios en medidas más tangibles. Desde esa vertiente social, defendió la implantación de un amplio sistema de protección y ayuda al alumnado «creando las Bolsas de estudio, capaces no solamente de mantener al estudiante, sino al propio tiempo sustituir en el seno familiar los aportes normales y ordinarios que el mismo hubiera podido conseguir». ${ }^{60}$ Igualmente, mostró su interés para que en las escuelas rurales se realizaran actividades con las familias - representaciones teatrales, proyecciones y actuaciones diversas-, para ir «influyendo a través de la escuela así concebida, sobre el nivel cultural y social de toda la comarca afectada». Un esquema similar plantea para las escuelas ubicadas en localidades de mediano tamaño. Reclama, incluso, en que deberían estar concebidas como Hogares del Niño, cuya misión, más allá de las actividades educativas con los escolares «ha de consistir, así mismo, en dirigir a la juventud y transformar el clima cultural de la localidad», en un claro ejemplo del concepto de escuela como dinamizadora de la vida social de la población, en aras de apoyar el desarrollo cultural de la misma. ${ }^{61}$

\footnotetext{
59 Tapia, Ensayo, 19 y 52.

60 Tapia, Ensayo, 16.

61 Tapia, Ensayo, 25.
} 
Uno de los momentos en que se aprecian mejor esas inquietudes, es en lo relativo a la enseñanza secundaria, cuyo modelo criticaba severamente. En su opinión, los institutos deberían completar la tradicional trasmisión de contenidos, con la incorporación de otras dimensiones formativas, como ya se había efectuado en los Institutos-Escuela, a los que valora positivamente, reconociendo que «vinieron a subsanar unos defectos de origen y función que nosotros remarcamos». A pesar de ello, remarca que la tarea se quedó a medias y resultaba necesaria una profunda reforma general de toda la segunda enseñanza, defendiendo el sistema de internados, y las diversas modificaciones al plan de estudios y de trabajo que ya hemos indicando. ${ }^{62}$

El documento firmado por Tapia, sorprende por su capacidad de integrar postulados tan distintos como los derivados del anarquismo, una visión estatal de la educación y la integración de las innovaciones pedagógicas del momento, en un claro intento de revitalizar y complementar los avances que se llevaron a cabo en España durante los años de gobierno republicano.

\section{DICTAMEN DEL MOVIMIENTO LIBERTARIO ESPAÑOL-CNT (FRANCIA, 1945)}

El último original que vamos a analizar es el Dictamen sobre enseñanza aprobado por el Comité Nacional del Movimiento Libertario Español-CNT, en el congreso celebrado en París los días 1 y 2 de mayo de $1945 .{ }^{63}$ El objetivo primordial de esa importante reunión, a la que acudieron representantes de diversos sectores del anarcosindicalismo, no fue otra que: «en los momentos históricos en que se debaten la vida y el porvenir del pueblo español [...] estudiar los múltiples problemas que, al retorno a los hogares, tendrá que afrontar». Uno de los ámbitos que centró la atención de los asistentes fue el educativo,

\footnotetext{
62 Tapia, Ensayo, 32-35.

${ }_{63}$ «Dictamen correspondiente al apartado f) del punto 9 que trata del orden cultural y de educación nacional», en Movimiento Libertario Español. C. N. T. en Francia. Comité Nacional, Memoria del Congreso de Federaciones Locales celebrado en París del 1. ${ }^{\circ}$ al 2 de mayo de 1945. Dictámenes (s.l.: Comité Nacional, 1945), 21-25. Se puede consultar en la sección de documentos de este monográfico. Debemos agradecer al profesor Antonio Viñao de la Universidad de Murcia la consulta de este documento y del texto de José de Tapia.
} 
no en vano se argüía que «uno de los fundamentos a solucionar es el de la Escuela». ${ }^{64}$

El tono y el contenido del Dictamen resultan sensiblemente diferentes a los dos escritos anteriores. Es mucho más breve y plantea, exclusivamente, principios generales sin llegar a descender, más que ocasionalmente, a perfilar acciones concretas. Toma como punto de partida la reivindicación de lo realizado con anterioridad en España, aspecto común a los documentos anteriores. Pero en esta ocasión, se realiza desde una representación exclusivamente partidista, incorporando referencias y personajes vinculados con el anarquismo, como Ferrer y Guardia, gran figura de la educación libertaria. Cita a continuación a numerosas escuelas racionalistas sostenidas por los círculos libertarios y acaba reivindicando las actuaciones de la Escuela Nueva Unificada. ${ }^{65}$

El texto está dividido en una primera parte o Preámbulo, que toma como punto de partida la Declaración de Derechos del Niño elaborada por el Consejo de la Escuela Nueva Unificada, y la defensa de la educación de la infancia en libertad. Igualmente, se defiende la integración de todas las entidades educativas bajo el concepto de escuela «del que hemos expurgado los impropios y desarticulados de primaria, secundaria, superior, para concebirla vertebrada, formando un todo homogéneo: el organismo educacional». Se propone la supresión de hospicios e internados, que serían reemplazados por las familiares Casas del Niño y la sustitución de los grupos escolares por edificios «con un mínimo de arquitectura y un máximo de naturaleza» instalados fuera de las ciudades y el aprendizaje del esperanto como primera lengua extranjera. ${ }^{66}$

La única medida de carácter más operativo de este primer apartado, guarda referencia con el profesorado. Tras insistir en la importancia del maestro, al cual se le debería exigir vocación, capacidad intelectual y cualidades morales y de carácter, se plantea el problema concreto sobre, qué hacer cuando la vuelta a España sea una realidad.

\footnotetext{
64 «Dictamen», 7.

${ }^{65}$ En realidad, Consejo de la Escuela Nueva Unificada (CENU). Emili Cortavitarte Carral, «El CENU, un sistema educativo público revolucionario en la Catalunya del 36», Viento Sur 147 (2016): 56-62.

66 «Dictamen», 2-3.
} 
Al respecto, se defiende la depuración de los maestros nombrados por el franquismo, «con los que se acepten, en los primeros días de nuestro regreso a España deberá[n] organizarse cursillos de perfeccionamiento». Y para poder actuar con la mayor diligencia, se señalaba que había que aprovechar «el tiempo que nos quede de estancia en Francia» para confeccionar listados de profesores entre los exiliados «a fin de tener preparados los cuadros en que apoyar la actuación desde los primeros días de nuestro regreso a España». ${ }^{67}$

En la segunda parte, titulada Dictamen, se enumeran 12 medidas más concretas, las cuales, como indicaba en la última de ellas, deberían interpretarse de acuerdo con lo dispuesto en el plan de la Escuela Nueva Unificada y lo aprobado en el «Congreso Cultural del Cine América de Barcelona». ${ }^{68}$ En estas, se vuelve a defender el sistema de la Escuela Unificada, gratuita y obligatoria, hasta que lo permitan las capacidades personales de cada alumno y no su procedencia social o las posibilidades económicas familiares, la escolarización obligatoria hasta los 18 años y que, a la finalización de cada etapa formativa, el alumnado recibiera el correspondiente certificado de estudios. ${ }^{69}$

Una cuestión en la cual el Dictamen se mantiene fiel al ideario libertario, es la función otorgada al Estado en la educación formal. Al respecto, se señalaba que: «La Enseñanza no es una función política, exclusiva del Estado, sino una necesidad social que compete a los Sindicatos y a las Federaciones de Enseñanza, con la Asociación de Padres de Alumnos». ${ }^{70}$ Más adelante se proponía crear "politécnicos de preparación y perfeccionamiento», específicamente para jóvenes que habiendo rebasado la edad escolar presentaban inquietudes formativas. También se efectuaba una referencia explícita a la «juventud del exilio», a la cual, por reparación moral y por interés de la propia sociedad, se debería considerar en edad escolar, para que pudiera completar su formación en los politécnicos citados anteriormente. ${ }^{71}$

\footnotetext{
67 «Dictamen», 3.

68 «Dictamen», 5.

69 «Dictamen», 3-4.

70 «Dictamen», 3.

71 «Dictamen», 4.
} 
Otras inquietudes desbordaban y ampliaban el marco del sistema educativo, planteando la creación de centros culturales o Ateneos en todas las ciudades, pueblos y aldeas y Escuelas del Militante en las grandes ciudades. Asimismo, se abogaba por la fundación de editoriales, la organización de bibliotecas cines, salas de espectáculos y emisoras de radio y Escuelas de Puericultura, específicamente "para las madres y compañeras en general». ${ }^{72}$

\section{CONVERGENCIAS Y DIVERGENCIAS EN LOS TRES DOCUMENTOS}

Como hemos ido apuntando, los tres trabajos presentan algunos rasgos comunes, así como notables diferencias en los planteamientos educativos que presentan. Entre los aspectos en común, hallamos que entre todos los autores existía cierto optimismo en cuanto a la condena internacional del franquismo, lo que facilitaría el retorno a España. De ahí se deriva el interés por ir confeccionando y dando a conocer políticas educativas que fueran dando forma al futuro sistema escolar a restaurar, en consonancia con la recuperación del inicial proyecto republicano. Esa sería, en nuestra opinión, la principal característica que los uniría, la preocupación por contar con un plan de actuación para el momento en que Franco cayera.

En cambio, en lo referente a la autoría y la intencionalidad de las propuestas, son más destacables las divergencias. El Dictamen elaborado por el Movimiento Libertario es un auténtico manifiesto programático de partido, elaborado por un órgano representativo del mismo, en este caso un congreso. El documento de la Comisión de estudio de los problemas españoles, fue impulsado por la Unión de Profesores Universitarios Españoles Exiliados, una organización profesional, aunque con una importante faceta socio-política. La ponencia estuvo formada por un grupo de eminentes profesores y pedagogos, que habían asumido destacadas responsabilidades públicas, una auténtica comisión de expertos. Por último, los Ensayos sobre la organización de la Educación Nacional, son producto del maestro José de Tapia en exclusiva, quien los escribió enlazando su ideología libertaria, las décadas de experiencia en las aulas y su reflexión sobre los problemas del sistema educativo español.

\footnotetext{
72 «Dictamen», 4-5.
} 
Los documentos también se diferencian por su estructura interna. El que resulta más sencillo de clasificar es la ponencia, ya que es casi un plan de actuación gubernamental, abarcando todas las competencias de la cartera de instrucción pública. Esto es, la política y el sistema educativo en su totalidad, con especial detalle en lo referente al contexto universitario, sin olvidar el ámbito de la cultura. Los Ensayos de Tapia también presentan un enfoque proactivo, aunque básicamente se circunscribe a las etapas de la educación básica, dedicando muy poco espacio a los estudios superiores y dejando de lado el fomento de la cultura fuera de las aulas. En lo que respecta al Dictamen, pese a ser producto de una entidad netamente política, se aleja mucho del modelo seguido por los dos anteriores, de tal modo que resulta poco verosímil tomarlo por un programa de intervención. Resulta demasiado general, sin apenas concreción y entremezclando temas netamente sociales con los de la política educativa, aderezado con algunas demandas tan radicales, como la enseñanza del esperanto o la integración de todas las instituciones docentes en ese genérico concepto de escuela, aspiraciones bastante utópicas para la época, mediado del siglo xx, y la realidad social y política.

En el estudio de las propuestas, nos limitaremos a cuatro elementos que consideramos de especial relevancia. El primero de ellos es la reivindicación de la educación republicana. En la ponencia, esa cuestión es puesta de manifiesto desde los primeros párrafos, sin duda resulta uno de los rasgos más significativos del documento. Por su parte, Tapia también realiza en varios momentos referencias muy positivas a la educación republicana, pero con un enfoque diferente. Las evoca como experiencias de su trayectoria que merecían ser recuperadas. En el Dictamen se produce algo parecido a lo que realiza la ponencia, pero con un alcance sensiblemente distinto. La reivindicación se ciñe al catalán Consejo de la Escuela Nueva Unificada y la defensa de una educación libertaria.

Otro de los puntos cruciales en las tres propuestas, lo recoge el papel que se atribuye al estado en la conformación y desarrollo educativo en España. La ponencia defendía una amplia intervención de la Administración, impulsando medidas más sociales, como becas, ampliando la escolarización y el acceso al bachillerato. En esa misma dirección apunta Tapia, aunque insistiendo en que resultaría muy conveniente 
que otras entidades, especialmente sindicatos, crearan sus propias escuelas y acentuando algo más los elementos sociales de las instituciones docentes y los aspectos democratizadores de la política educativa. El Dictamen, finalmente, se manifestaba fiel al pensamiento educativo libertario, pero sin negar las posibles intervenciones gubernamentales, reafirmándose en la idea de que la educación era una necesidad social y, como tal, debía de ser competencia de los sindicatos y de las familias, dejando al estado en un segundo plano.

Es destacable el interés que concita en las tres publicaciones el profesorado, especialmente en cuanto a su formación y las funciones que ha de desempeñar en su trabajo. Al respecto, tanto la ponencia como el texto de Tapia, inciden en las funciones que deberían de desempeñar los Seminarios de Pedagogía. Ambos presentan bastantes puntos de contacto, ya que les otorgan amplias competencias en todo lo referente a la formación inicial y permanente del magisterio y del profesorado de enseñanza secundaria. En el caso de la ponencia redactada por la Comisión para el estudio de los problemas españoles, los vincula a las Secciones de Pedagogía que habían sido creados en las Universidades de Madrid y Barcelona. Tapia, por su parte, propone que los Seminarios de Pedagogía sustituyan por completo a las normales. Resulta llamativa esa coincidencia, que impulsaba y ampliaba la apuesta de la educación republicana por los estudios de pedagogía. En cuando al Dictamen, no incluye ninguna mención a la formación de los docentes.

Una preocupación común es qué hacer con la educación franquista, una vez se hubiera producido la restauración republicana y con las personas que hubieran ejercido el magisterio en esa etapa. Al contrario que con otros temas, los enunciados más esclarecedores se localizan en el Dictamen, en donde se menciona, expresamente, que los maestros nombrados por el franquismo deberían ser destituidos y «que de ninguna manera podrán continuar en la escuela». Con los que estuvieran ejerciendo con nombramientos anteriores al inicio de la guerra, y que tras un proceso de depuración se considerara que pudieran continuar en sus puestos, serían sometidos a «cursillos de perfeccionamiento». ${ }^{73}$ No hemos localizado ninguna referencia sobre esta cuestión en el texto de Tapia. Y en cuanto a la ponencia, ya se señaló que se decantaba por adecuar la inter-

\footnotetext{
73 «Dictamen», 3.
} 
vención a la situación que pudiera encontrarse, aunque siempre desde la moderación y pasando de puntillas por tan desagradable asunto.

En relación con la orientación principal de los documentos, tanto la ponencia como el texto de Tapia, presentan enfoques reformadores e innovadores. Ambos parten de las transformaciones emprendidas por el proyecto modernizador republicano y presentan bastantes coincidencias en las medidas de mejora que plantean. Dentro de ese marco, José de Tapia resulta bastante más innovador que el documento esbozado por la ponencia. Pero pensamos que, tanto en su fondo como en su forma, prevalece la perspectiva reformadora y no puede ser catalogado de revolucionario. Más bien al contrario, resulta continuista con el proyecto educativo republicano. Los dos abogan por una mayor inversión e intervención estatal; el impulso y apoyo a la innovación de las metodologías didácticas; la democratización en el acceso del bachillerato y una mayor atención a las cuestiones sociales. Las diferencias inciden en el alcance e intensidad de las propuestas, resultando de mayor calado en el texto escrito en Francia, que en el documento redactado en México.

Por su parte, el Dictamen puede catalogarse de proposición rupturista, con propuestas muy radicales y de difícil acople a la realidad española, dado el escaso razonamiento con que están planteadas. No resulta difícil atisbar tras él la versión más estricta de la doctrina libertaria. Pese a su común coincidencia ideológica, el texto de José de Tapia, es más posibilista, mostrándonos una lectura del ideario anarcosindicalista orientado a la confluencia y buscando el consenso con otros grupos políticos. Y en lo que respecta a la ponencia, desde sus primeros enunciados, proclama su directo entronque con idearios institucionistas y socialistas, los cuales habían regido el proyecto modernizador de la política educativa en los primeros años de la Segunda República. Se trata pues, de tres documentos de gran valor pedagógico y político, que nos trasladan a un momento crítico y esperanzador, no solo para la España exiliada, sino también para el mundo en general.

\section{LA OTRA REALIDAD}

La perspectiva de un pronto regreso a España, se entremezcló, en muchas ocasiones, con las necesidades más perentorias de formación de los 
más jóvenes entre las familias exiliadas. La caída de franquismo se daba por inminente, sin embargo, los niños y niñas llevaban tiempo asistiendo a las escuelas de su país de acogida y ese hecho no podía soslayarse. Esta situación fue vivida de un modo dispar dependiendo del lugar en donde residieran los españoles. En México, el segundo país que acogió a un mayor número de refugiados, las propuestas escolares de los republicanos se concretaron en la creación de centros educativos propios de carácter privado, promovidos por el colectivo republicano, para dar acogida al profesorado emigrado y a los hijos e hijas de los desterrados. ${ }^{74}$

Por el contrario, en Francia tuvieron que tomar otros derroteros, ajustándose a la situación política y escolar de ese país. La decisión del gobierno francés de incorporar en su sistema educativo a los miles de niños y niñas que llegaron cruzando la frontera, junto al hecho de que el francés era la lengua vehicular, cercenó la posibilidad de que maestros españoles pudieran crear y dirigir centros educativos propios. No obstante, en suelo galo se desarrollaron una serie de iniciativas escolares y formativas, que perseguían los mismos intereses mostrados por el Dictamen de la CNT analizado anteriormente.

Precisamente, el temor ante la pérdida de la lengua materna entre las generaciones españolas más jóvenes, se convirtió en el acicate que puso en movimiento a familias y docentes, los cuales se dirigieron al entonces ministro de Instrucción Pública en el exilio, Miguel Santaló, solicitándole apoyo económico y materiales para promover centros de estudios donde poder formar a la juventud en el idioma y la cultura española, ante el temor de que olvidaran la lengua o no la aprendieran correctamente.

Resulta paradójico comprobar que, pese a estar tan cerca físicamente estos menores del país de origen, se encontraban más alejados

\footnotetext{
${ }^{74}$ Para conocer más sobre los colegios del exilio en México, consultar, entre otras publicaciones: José Ignacio Cruz Orozco, La educación republicana en América (1939-1992) (Valencia: Generalitat Valenciana, 1994); del mismo autor: «El patronato Cervantes de México y los colegios de provincias del exilio pedagógico de 1939", Historia de la educación: Revista interuniversitaria 14-15 (19951996): 453-465. Sandra García de Fez, «México y España en los discursos identitarios de los colegios del exilio en la Ciudad de México (1939-1950)», en El exilio republicano de 1939 y la segunda generación, coords. Manuel Aznar Soler y José Ramón López García (Sevilla: Renacimiento, 2011), 267-274; de la misma autora: «La cohesión nacional a través de la prensa escolar de los colegios del exilio español en la ciudad de México (1939-1960)», Historia de la educación: Revista interuniversitaria 36 (2017), 103-121.
} 
cultural y lingüísticamente de España que los residentes en México, escolarizados muchos de ellos en los colegios del exilio y sin sufrir todos ningún tipo de expatriación lingüística. En esta línea, fueron muchas las peticiones al Ministerio de Instrucción Pública, para dar respuesta a estas necesidades formativas, entre ellas la formulada por el padre de un joven que solicitaba la organización de un curso de español por correspondencia, con el fin de atender a quienes habían realizado sus estudios primarios enteramente en francés. Según él, se trataría de paliar la desventaja de estos muchachos respecto a los estudiantes que permanecieron en España.

Me atrevo a sugerir dicha idea en gracia á los beneficios que reportaría á toda esa juventud, que deseándolo ardientemente carecen de dichos conocimientos, indispensables á todo español que no quiera pasar el día de mañana por la vergüenza y el bochorno que representaría el no poder escribir correctamente en español y seria grande injusticia dejarles en ese desamparo y en una situación de inferioridad ${ }^{75}$

La respuesta que recibió por parte del Ministerio fue que se dirigiera a los servicios de la Young Men's Christian Association (YMCA,) ${ }^{76}$ concretamente al departamento de Servicio de Ayuda a los Refugiados Españoles, creado por la delegación en Francia de la Alianza Universal de las Asociaciones Cristianas de Jóvenes. Esta asociación, en colaboración con el Ministerio de Instrucción Pública, había puesto ya en marcha unos cursos por correspondencia para formar tanto a jóvenes españoles como a docentes de primaria.

Dentro de esta misma línea de actuación, el 14 de noviembre de 1946 el Ministerio de Instrucción Pública hizo públicas unas instrucciones para iniciar una formación no presencial, dirigida a formar a maestros en el exilio, especialmente de primaria. La duración del curso sería de seis meses suponiendo un pago único de cien francos. El profesorado estuvo compuesto por un grupo de docentes universitarios y maestros que impartieron cátedra en las Escue-

75 Andrés Coll, «Carta al Director de Servicios de Cultura», 19 de agosto de 1948, P-443-2, Archivo de la Segunda República Española en el Exilio (ASRE).

${ }^{76}$ Asociación Cristiana de Jóvenes. 
las Normales españolas. ${ }^{77}$ Algunos de estos profesores fueron Jesús María Bellido Golferichs, Rodolfo Llopis Ferrándiz y José Ballester Gozalvo.

El curso se inició formalmente en 1947, con contenidos curriculares basados en lengua y literatura españolas, geografía, historia, aritmética, geometría, física, química, biología, psicología y pedagogía. Una vez superado un cuestionario inicial con preguntas generales, los aspirantes recibían una formación personalizada y adaptada a su nivel mediante materiales que eran enviados a sus domicilios. Pese a tan buenos auspicios, contando con un profesorado de tan alta calidad y el apoyo del gobierno español en el exilio, la valoración de dicho curso no fue tan positiva como cabía esperar. ${ }^{78}$

En cuanto a la creación de centros de estudio para la enseñanza de español y cultura española, estos no pudieron contar con el apoyo económico del Ministerio de Instrucción en el exilio. Este argumentó que no disponía de los medios necesarios, aunque valoraba y apoyaba el hecho de que se atendiera a los niños formándolos en la «cultura nuestra». ${ }^{79}$ Algunas de estas acciones, se concretaron en las denominadas Escuelas de Cultura Española. ${ }^{80}$ Sabemos que estas escuelas no formaron parte de un plan educativo del Ministerio de Instrucción, ya que algunas funcionaban antes de la reconstitución del gobierno republicano en el exilio y otras informaban de su existencia años después del inicio de sus tareas.

Otro ejemplo de propuestas llevadas a cabo por docentes y personal sanitario español en Francia, fue la puesta en marcha de una escuela de ciegos y mutilados de la mano derecha, con la intención de atender a aquellas personas que sufrieron lesiones importantes durante los com-

\footnotetext{
77 «Instrucciones del Ministerio de Instrucción Pública», 14 de noviembre de 1946, P-500-14, ASRE.

78 «Relación de las actividades más importantes del Ministerio de Instrucción Pública», 29 de agosto de 1947, P-88-5, ASRE.

79 «Carta de respuesta de Miguel Santaló a Pedro Caamaño, vicepresidente del Comité France-Spagne de l'Estaque Riaux», 26 de marzo de 1947, P-499/5, ASRE.

${ }^{80}$ En parte de la documentación aparece esta forma de definir los centros creados por españoles refugiados en Francia con apoyo o sin apoyo de las instituciones republicanas del exilio desde su llegada a partir de 1939.
} 
bates y bombardeos en España y que llegaban a Francia en situación de mayor desventaja. ${ }^{81}$

A las iniciativas anteriores hay que sumar otra de la FETE. La delegación de Burdeos, escribió a Salvador Quemades, para comunicarle la existencia de un amplio colectivo de niños y jóvenes españoles en el Departamento de la Gironde, incluyendo «a los que proceden de la antigua colonia española, denominada comúnmente, emigración económica». Se hablaba de un millar de menores que sufrían una situación de «aislamiento espiritual» de la patria, razón por la cual este organismo sindical pretendía poner en marcha,

un sistema departamental de actividades culturales españolas que enlazarían todos estos niños y adolescentes. Y pensamos constituir el Centro o Núcleo de nuestras actividades en base a una Imprenta Escolar, tipo Freinet. ${ }^{82}$

El propósito claro de los educadores consistía en agrupar y trabajar con estos menores para fomentar la identidad nacional de origen, mediante una de las técnicas más innovadoras de la época: la imprenta Freinet. Para ello solicitaban dinero para la compra de la imprenta, ruego que fue atendido por el ministro otorgando 6.000 francos para su adquisición, notable excepción, ya que la falta de recursos del gobierno republicano era una constante. Por ello, un grupo de profesores propusieron al Ministro solicitar al gobierno francés, la posibilidad de incluir clases de cultura española en las aulas francesas dirigidas al alumnado hispano, rentabilizando las estructuras educativas existentes.

A tal efecto, en mayo de 1947 cuatro educadores exiliados en Marsella escribieron a Miguel Santaló con una propuesta concreta: que el gobierno español en el exilio apoyara el inicio de «cursos de Lengua Castellana, Geografía e Historia de España en los Grupos Escolares de las Escuelas Francesas de esta ciudad de Marsella». ${ }^{83}$ Los firmantes conta-

\footnotetext{
${ }^{81}$ Pablo Gardeny, «Una escuela de ciegos y mutilados», La nouvelle espagne (París), 2 de noviembre de 1946.

82 «Carta de la FETE (UGT), Comisión Departamental de Burdeos al Ministro de Instrucción pública, Salvador Quemades», 12 de abril de 1948, P-582-3, ASRE.

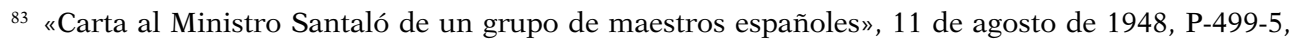
ASRE.
} 
ban con los permisos oportunos por parte de las autoridades escolares galas, faltándoles el soporte por escrito del Ministerio y las credenciales individuales que les avalaran para ejercer como docentes. Así mismo dejaban ver al Ministro la conveniencia de percibir algún salario por dicho trabajo, argumentaban a su favor que asociaciones internacionales y francesas les apoyaban en sus propósitos, citando como ejemplo a los Amigos de la Instrucción Laica Francesa.

En la misma línea, la Unión Federal de Estudiantes Hispanos (UFEH),${ }^{84}$ en un documento redactado en 1945 por la comisión que tenía su sede en París, daba cuenta de la fundación de un Instituto de Segunda Enseñanza en Toulouse «con profesorado y programa español, al cual podrán asistir todos aquellos que deseen continuar o comenzar el Bachillerato español». ${ }^{85}$ Se desconoce si este proyecto llegó a cuajar; en cualquier caso, el que se propusiera su creación a tres meses de finalizada la conflagración mundial, denota, de nuevo, el optimismo en el regreso a la patria y en la autopercepción excesivamente optimista de su papel protagonista en la reconstrucción de la patria, en el mismo tono que los tres documentos analizados en las páginas anteriores,

El objeto que la UFEH persigue es el de encauzar en la senda del estudio al máximo de jóvenes y recuperar para nuestra España el mayor número de valores intelectuales que han de formar sus cuadros mañana, hoy que existen posibilidades para ello [...]. Que no influya en tu decisión la perspectiva de una inminente vuelta a España puesto que el curso empezado aquí puede ser acabado en España. NI UN AÑO MÁS DEBE DE SER PERDIDO. ${ }^{86}$

Sin embargo, el régimen del general Franco no cayó tras la finalización de la guerra mundial, No se produjo una condena efectiva por parte de las potencias aliadas del gobierno y el régimen impuesto en España tras la cruel Guerra Civil. La deriva de la coyuntura internacio-

\footnotetext{
${ }^{84}$ La UFEH fue legalizada en 1929 y estaba compuesta por las distintas comisiones de la Federación Universitaria Escolar repartidas por la geografía española. Formó parte de diversos organismos internacionales de estudiantes y se mantuvo en el exilio.

85 «Congresos Universitarios. Escrito de la Comisión de la UFEH», 27 de agosto de 1945, P-500-9, ASRE.

${ }^{86}$ «Congresos Universitarios. Escrito de la Comisión de la UFEH», 27 de agosto de 1945, P-500-9, ASRE. Mayúsculas en el original.
} 
nal hacia el esquema de la "guerra fría», favoreció la consolidación del franquismo durante cuarenta años, lo que arrumbó y permitió que cayeran en el olvido los proyectos de política educativa que hemos analizado en estas páginas.

\section{Nota sobre los autores}

José Ignacio Cruz Orozco es Doctor en Filosofía y Ciencias de la Educación (1987). Profesor Titular de Universidad en el Departamento de Educación Comparada e Historia de la Educación de la Universitat de València desde 1992. Especialista en historia y en política de la educación. Sus líneas de investigación fundamentales son: el sistema educativo español, la educación secundaria y políticas de juventud. Tiene reconocidos dos tramos de investigación (sexenios) y cuatro tramos de actividad docente (quinquenios). Ha publicado una quincena de libros entre los que se encuentran: El yunque azul. Frente de Juventudes y sistema educativo. Razones de un fracaso, Madrid: Alianza, 2001; Los colegios del exilio en México, Madrid: Residencia de Estudiantes, 2005; Prietas las filas. Las falanges Juveniles de Franco, Valencia: Universitat de València, 2012; La cultura académica del exilio español en México: Viejas prácticas para nuevos tiempos, México: UAEH-Universidad de Valencia-Díaz de Santos, 2013 (editor conjuntamente con Leticia Canales Rodríguez); Consideraciones sobre la enseñanza secundaria española (1835-1970), en Tavares Santos, J.M., Regina Paz, S., Enseino Médio: Profissao Docente, Currículo e Novas Tecnologías, Curitiba: CRV, 2013, 245-260. Asimismo, ha publicado más de sesenta artículos sobre diversos aspectos de la educación española en diversas publicaciones especializadas españolas y extranjeras, entre los que cabe señalar: «Los institutos de segunda enseñanza en España. Datos sobre su implantación (1835-1936)», Educatio Siglo XXI 30, no.1 (2012): 233-252; «La extensión de la Enseñanza Media en la España rural. Los Colegios Libres Adoptados (1960-1980)», Revista Española de Pedagogía 256, (2013): 293-308.

Sandra García de Fez es Diplomada en Trabajo Social y Doctora en Pedagogía, profesora Contratada Doctora en el Departamento de Educación Comparada e Historia de la Educación, Universitat de València. Tras cuatro años de estancia en El Colegio de México como investigadora invitada para la realización de su tesis sobre los colegios del exilio en 
México, ha publicado varios artículos sobre el tema: «La cohesión nacional a través de la prensa escolar de los colegios del exilio español en la ciudad de México (1939-1960)», Historia de la educación: Revista interuniversitaria 36, (2017): 103-121; "Una Escuela desconocida del exilio: la polémica en torno al Instituto Hispano Mexicano Ruiz de Alarcón», Educació i història: Revista d'història de l'educació 17, (2011): 213-235; «Aquellos pequeños emigrados: los niños y niñas del exilio republicano español en la ciudad de México, 1939-1945», Estudios Migratorios Latinoamericanos 24, no. 69 (2010): 299-312. Sus líneas de investigación se complementan con el análisis de distintas políticas educativas (la formación del profesorado, el absentismo escolar, el derecho a la educación). Algunas publicaciones: coautora junto con Raúl Solbes Monzó de «Los equipos directivos en la formación profesional española: una propuesta de formación continua», Revista Iberoamericana de Educación 70, no. 1 (2016): 161-182, y, con Javier Bascuñán Cortés, de «La mejora de la calidad en la formación inicial del profesorado de Educación Secundaria a partir de la experiencia de gestión del máster de la Universidad de Valencia», en La formación inicial del profesorado de educación secundaria, coords. Juan Manuel Fernández Soria et al. (València: Tirant Lo Blanch, 2016), 251-266.

\section{REFERENCIAS}

Alted, Alicia. La voz de los vencidos. El exilio republicano de 1939. Madrid: Aguilar, 2005.

Carrasquer, Félix. Lo que aprendi de los otros. Zaragoza: Prensas de la Universidad de Zaragoza; Instituto de Estudios Altoaragoneses; Instituto de Estudios Turolense y Gobierno de Aragón, 2017.

Cifuentes Lemus, Juan Luis. «Enrique Rioja Lo Bianco (1895-1963»). Revista de la Universidad 536-537 (1995): 64-65.

Cobos, José M. et al. «Reunión de la Unión de Profesores Universitarios Españoles, UPUEE». Abaco: Revista de cultura y ciencias sociales 42 (2004): 61-74.

Cortavitarte, Emili. «El CENU, un sistema educativo público revolucionario en la Catalunya del 36». Viento Sur 147 (2016): 56-62.

Claret Miranda, Jaume. «La Unión de Profesores Universitarios Españoles en el Exilio». Historia y Memoria de la Educación 9 (2019): ***_***

Cruz, José Ignacio. La educación republicana en América (1939-1992). Valencia: Generalitat Valenciana, 1994. 
Cruz, José Ignacio. «El patronato Cervantes de México y los colegios de provincias del exilio pedagógico de 1939». Historia de la educación: Revista interuniversitaria 14-15 (1995-1996): 453-465.

Cruz Orozco, José Ignacio. «La propuesta sobre educación de la comisión para el estudio de los problemas españoles (1945)». Historia y Memoria de la Educación 9 (2019): *******

De Hoyos, Jorge. «La historiografía sobre refugiados y exiliados políticos en el siglo xx: el caso del exilio republicano español de 1939». Ayer. Revista de Historia Contemporánea 106, (2017): 293-305.

García de Fez, Sandra. "México y España en los discursos identitarios de los colegios del exilio en la Ciudad de México (1939-1950)», en El exilio republicano de 1939 y la segunda generación, coords. Manuel Aznar Soler y José Ramón López García, 267-274. Sevilla: Renacimiento, 2011.

García de Fez, Sandra. "La cohesión nacional a través de la prensa escolar de los colegios del exilio español en la ciudad de México (1939-1960)», Historia de la educación: Revista interuniversitaria 36 (2017): 103-121.

Garritz, Andoni. «Francisco Giral González: un verdadero maestro». Revista de la Sociedad Química de México 46, no.2 (2002): 74-76.

Giral, Francisco. "Actividad de los gobiernos y de los partidos republicanos», en El exilio español de 1939, vol. II, dir. José Luis Abellán, 204-207. Madrid: Taurus, 1976.

González López, Etelvino. «El pedagogo Luis Álvarez Santullano». Cuadernos de la Cátedra Miguel de Unamuno 48 (2010): 119-175.

Jiménez Mier, Fernando. Un maestro singular. Vida, pensamiento y obra de José de Tapia B. México: Ediciones Robin, 1989.

Juan Borroy, Víctor Manuel. «El pedagogo aragonés Domingo Tirado Benedí. Notas sobre su vida y obra». Anales. Anuario del Centro de la Universidad Nacional de Educación a Distancia en Calatayud 9 (2001): 117-128.

López Sánchez, José María. «El exilio científico republicano en México: la respuesta a la depuración», en La destrucción de la ciencia en España. Depuración universitaria en el franquismo, dir. Luis Enrique Otero Carvajal, 177239. Madrid: Editorial Complutense, 2006.

Martín Ramos, José Luis. «La Unió Socialista de Catalunya (1923-1936)». Recerques: Història, economia i cultura 4 (1974): 155-190.

Peláez Reoyo, Tomás. Peinado Altable (1909-95). Aportaciones a La Psicología y Educación. Valladolid: Universidad de Valladolid, 1998.

Rangel Mayoral, Modesto Miguel. Rubén Landa Vaz, un pedagogo extremeño de la Institución Libre de Enseñanza en México. Badajoz: Editora Regional de Extremadura, 2006. 